\title{
The Economic Dispatch of the Power Generated from the Proposed Nigerian 330kV Integrated Network using ETAP 12.6 Software.
}

\author{
10gbikaya S. (ogbikaya.stephen@edouniversity.edu.ng) \\ ${ }^{2}$ Ike S. (sam.ike@uniben.edu) \\ ${ }^{3}$ Evbogbai M. J. E. (evbogbaiedekin@edouniversity.edu.ng) \\ ${ }^{1 \& 3}$ Department of Electrical and Electronic Engineering, Edo University Iyamho, Nigeria. \\ ${ }^{2}$ Department of Electrical and Electronic Engineering, University of Benin, Nigeria. \\ All correspondence should be directed to Engr. Ogbikaya S. (ogbikaya.stephen@edouniversity.edu.ng) \\ DOI: $10.31364 / \mathrm{SCIRJ} / \mathrm{v} 7 . \mathrm{i} 4.2019 . P 0419645$ \\ http://dx.doi.org/10.31364/SCIRJ/v7.i4.2019.P0419645
}

\begin{abstract}
This work analyses the Economic Dispatch of the power generated from the Proposed Nigerian 330KV integrated network using ETAP 12.6 software and the result simulated by Matlab software. The result obtained revealed that not all the generating stations of the Proposed Nigerian 330KV network will be in circuit during optimal power flow. The generating stations that are out of circuit are thermal power stations. This reduces the cost of generation, waste as well as saves energy from the installed capacity of generation. The result further reveal that the real and reactive transmission losses in the entire network is reduced to $45.41 \mathrm{MW}$ and $257.98 \mathrm{MVar}$ respectively.
\end{abstract}

Keyword: Economic Dispatch, Optimal, Power, Flow, ETAP 12.6, Matlab.

\section{INTRODUCTION}

The extensive interconnection of power sources has made the generation of a system in the most economical manner a complex subject. Economy must be balanced against security of supply. Economic load dispatch problem is one of the most important factor in power system operation and planning. The main objective of this is to determine the optimal combination of power outputs of all generating units so as to meet the required demand at minimum cost while satisfying the constraints and the load demand of the network. Apart from financial consideration, it is becoming difficult for generators to cope with information produced by large complex systems in the time of emergency such as major faults. Computers with on-line facilities can more readily digest two information and take careful measure and action by instructing control gear and settings or by displaying of relevant information to enable human operators to take appropriate action. In the attempt to obtain economic optimization, the limitation of the system such as plant ratings and stability limits must be observed. The use of digital computers for load flows and fault calculations and the development of optimization techniques in control theory have resulted in much attention being given to this topic. So many models with different techniques have been used to solve these problem. In this research work, this problem was solve by optimal power 
flow under the ETAP 12.6 software environment. Ogbikaya, Ike and Evbogbai (2019) in their study of the analysis of the proposed Nigerian $330 \mathrm{kV}$ integrated network using ETAP 12.6 software reveals that with the integration of the proposed 330kV network, electricity supply in the grid will be more stable, available, reliable and efficient as a result of the improved voltage profile on the buses and reduced transmission losses of real and reactive power to $62.28 \mathrm{MW}$ and $-3850.72 \mathrm{MVar}$ respectively on the entire network. Ogbikaya, Ike and Evbogbai (2019) stated in their study of the impact of the proposed Nigerian 330kV integrated network on the transfer capacity of the existing $330 \mathrm{kV}$ network that the transfer capacity of the entire network is increased by $2 \mathrm{GW}$ with the proposed integrated $330 \mathrm{KV}$ network. This will help the system to accommodate more load and reduce load shedding drastically and also eradicate system collapses in the network as a result of voltage instability. Onahaebi (2007) stated in his study of Reduction of the high technical power losses associated with the Nigerian 330KV Transmission Network using Power World Simulator (PWS) that the proposed modifications to the $330 \mathrm{kV}$ transmission network incorporating additional lines to form more loops with minimal compensation meets the acceptable limit of $\pm 5 \%$ and reduces the energy losses from $337.5-189.9$ MWH, representing $45 \%$ improvement over the existing network. This research noted that with the proposed integrated $330 \mathrm{kV}$ network, the existing $330 \mathrm{kV}$ network is improved but running all the generating stations of the proposed integrated 330KV network during off-peak period when the load demand in the network is minimal will be a waste of power, hence the economic load dispatch. In this work, optimal power flow (OPF) using ETAP 12.6 software was simulated to maximise the power generated in the proposed integrated 330KV network with a minimal active and reactive transmission losses in the entire network.

\section{MATERIALS AND METHOD}

ETAP 12.6 software, proposed integrated 330kV grid network, MATLAB software and data from Transmission Company of Nigeria (TCN) were used in this work.

The proposed integrated $330 \mathrm{kV}$ grid network was modelled using ETAP 12.6 software shown in Figure 1, the resulting network was simulated (optimal power flow environment) with ETAP 12.6 software using Newton Raphson Iteration Algorithm with a precision of 0.0001 as a result of it easy convergence, this is shown in Figure 2. The result obtained was analysed using MATLB software.

WWW.scirj.org

(C) 2019, Scientific Research Journal

http://dx.doi.org/10.31364/SCIRJ/v7.i4.2019.P0419645 


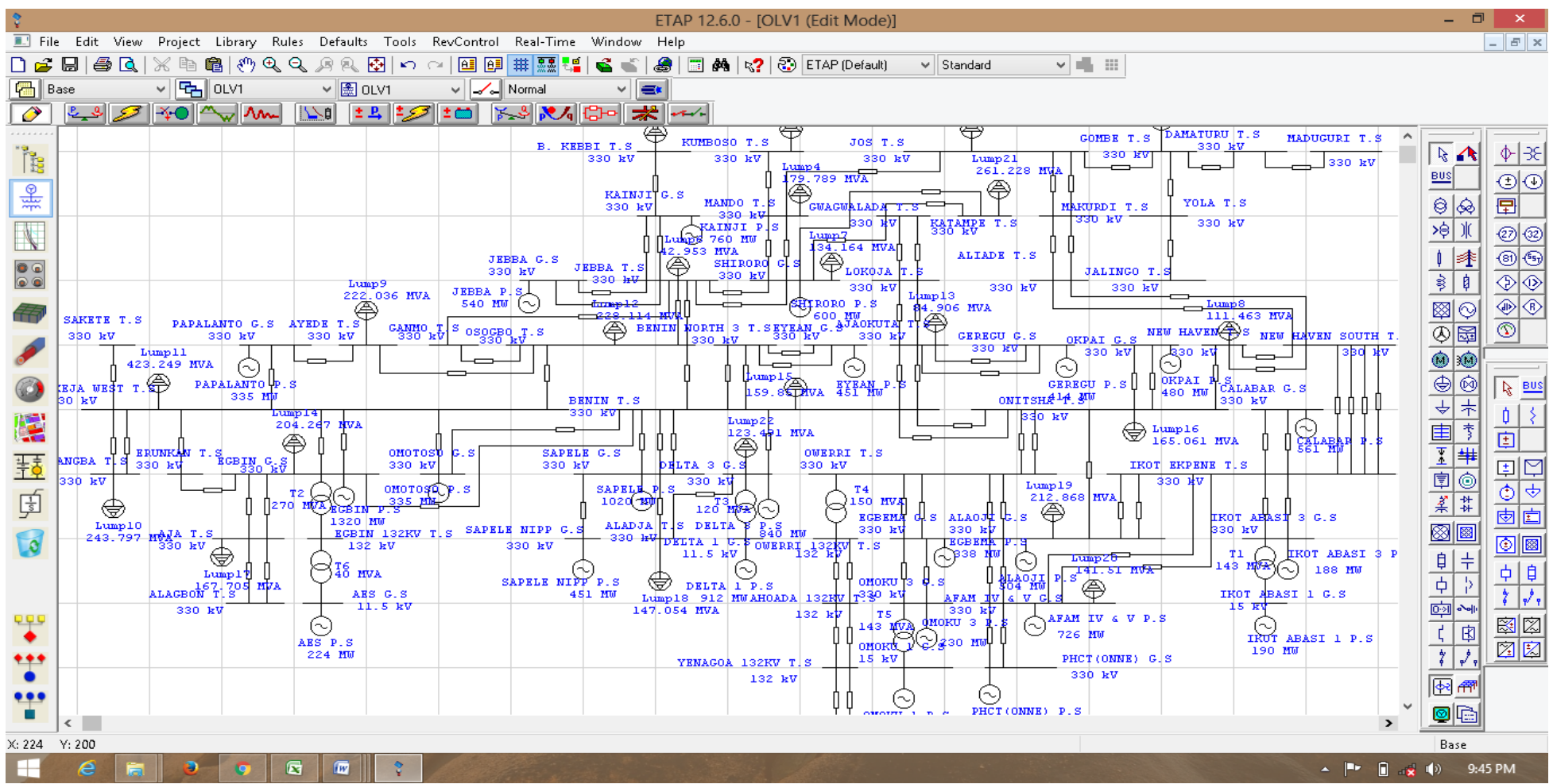

Figure 1: Model of Proposed Integrated 330KV Network using ETAP 12.6 Software

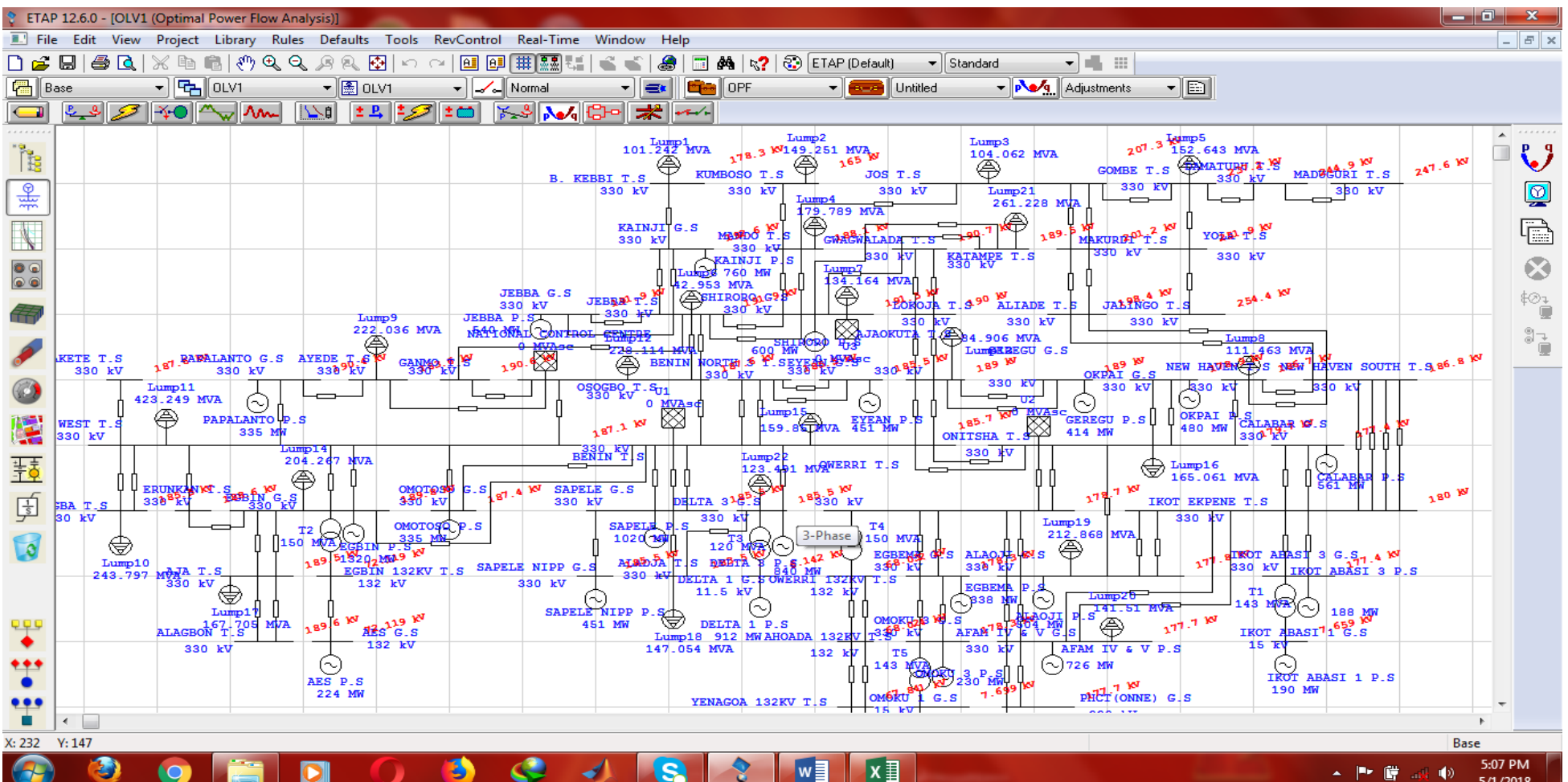

Figure 2: Optimal Power Flow Simulation (Run Mode) of Proposed Integrated 330KV Network using ETAP 12.6 Software. 


\section{RESULT AND DISCUSSION}

The result obtained from the optimal power flow of the Proposed Integrated 330KV Network is tabulated in Table 1. The result obtained from this simulation indicates that during optimal power flow, all the generators that are out of circuit are all thermal power plant while all the hydro power stations are in circuit as it has zero cost of fuel for it to generate power. This will reduce the cost of fuel for generation using the thermal power plant. The result is analysed as follows:

Egbin P.S supplies power to the buses connected to both Egbin P.S and AES P.S in the network as it closer to the buses and has minimal losses along the transmission lines compared to AES P.S that is further away from the buses with higher transmission losses.

For Delta 3 P.S and Delta 1 P.S connected to the same buses, only Delta 3 P.S operates as a result of proximity to the buses with reduced transmission losses.

For Ikot Abasi 3 P.S and Ikot Abasi 1 P.S connected to the same buses, only Ikot Abasi 3 P.S operates as a result of proximity to the buses.

For Egbema P.S and Omoku 1 \& 3 P.S connected to the same buses, only Egbema P.S operates as a result of reduced transmission losses due to its proximity to the buses.

For Afam iv \& v P.S and PHCT (ONNE) P.S connected to the same buses, only Afam iv \& v P.S operates as it is close to the buses and has reduced transmission losses.

For sapele P.S and Sapele NIPP P.S connected to the same buses, only Sapele P.S operates due to reduced transmission losses as a result of proximity to the buses compared to Sapele NIPP P.S that is far away.

Table 1: Result obtained from Optimal Power Flow of the Proposed Integrated 330KV Network

\begin{tabular}{|c|l|c|c|}
\hline \multirow{2}{*}{$\begin{array}{c}\text { Power Station } \\
\text { ID }\end{array}$} & \multicolumn{3}{|c|}{ Optimal Setting } \\
\cline { 2 - 4 } & \multicolumn{3}{|c|}{ Generator/Power Grid } \\
\cline { 2 - 4 } & \multicolumn{1}{|c|}{ Power Station } & MW & MVar \\
\hline 1 & AES P S & 0 & 0 \\
\hline 2 & AFAM IV \& V P.S & 141.479 & -98.285 \\
\hline 3 & ALAOJI P.S & 276.611 & -237.385 \\
\hline 4 & CALABAR P.S & 48.023 & -158.513 \\
\hline 5 & DELTA 1 P.S & 0 & 0 \\
\hline 6 & DELTA 3 P.S & 166.115 & -79.295 \\
\hline 7 & EGBEMA P.S & 34.65 & 231.003 \\
\hline 8 & EGBIN P.S & 633.675 & -38.215 \\
\hline 9 & EYEAN P.S & 61.19 & \\
\hline & & $\frac{\text { cirj.org }}{\text { : Research Journal }}$ & iCIRJ/v7.i4.2019.P0419645 \\
\hline
\end{tabular}




\begin{tabular}{|c|l|c|c|}
\hline 10 & GBARAN-UBIE P.S & 0.166 & -4.982 \\
\hline 11 & GEREGU P.S & 139.578 & -88.966 \\
\hline 12 & IKOT ABASI 1 P.S & 0 & 0 \\
\hline 13 & IKOT ABASI 3 P.S & 46.102 & -154.205 \\
\hline 14 & JEBBA P.S & 165.087 & -56.19 \\
\hline 15 & KAINJI P.S & 85.736 & 1.299 \\
\hline 16 & OKPAI P.S & 61.979 & -77.301 \\
\hline 17 & OMOKU 1 P.S & 0 & 0 \\
\hline 18 & OMOKU 3 P.S & 0 & -10.477 \\
\hline 19 & OMOTOSO P.S & 31.488 & -17.179 \\
\hline 20 & PAPALANTO P.S & 286.806 & 144.047 \\
\hline 21 & PHCT(ONNE) P.S & 0 & -15.619 \\
\hline 22 & SAPELE NIPP P.S & 0 & -0.091 \\
\hline 23 & SAPELE P.S & 105.922 & -42.347 \\
\hline 24 & SHIRORO P.S & 548.321 & -31.773 \\
\hline
\end{tabular}

Figure 3 shows the Optimal Power flow of the Proposed Integrated 330KV Network. This graph shows the real and reactive operating power of the generating stations in MW and MVar. The normal bar indicates the real operating power in MW while the inverted bars indicates the reactive operating power in MVar.

Figure 3: Graph of Optimal Power Flow of the Proposed Integrated 330KV Network

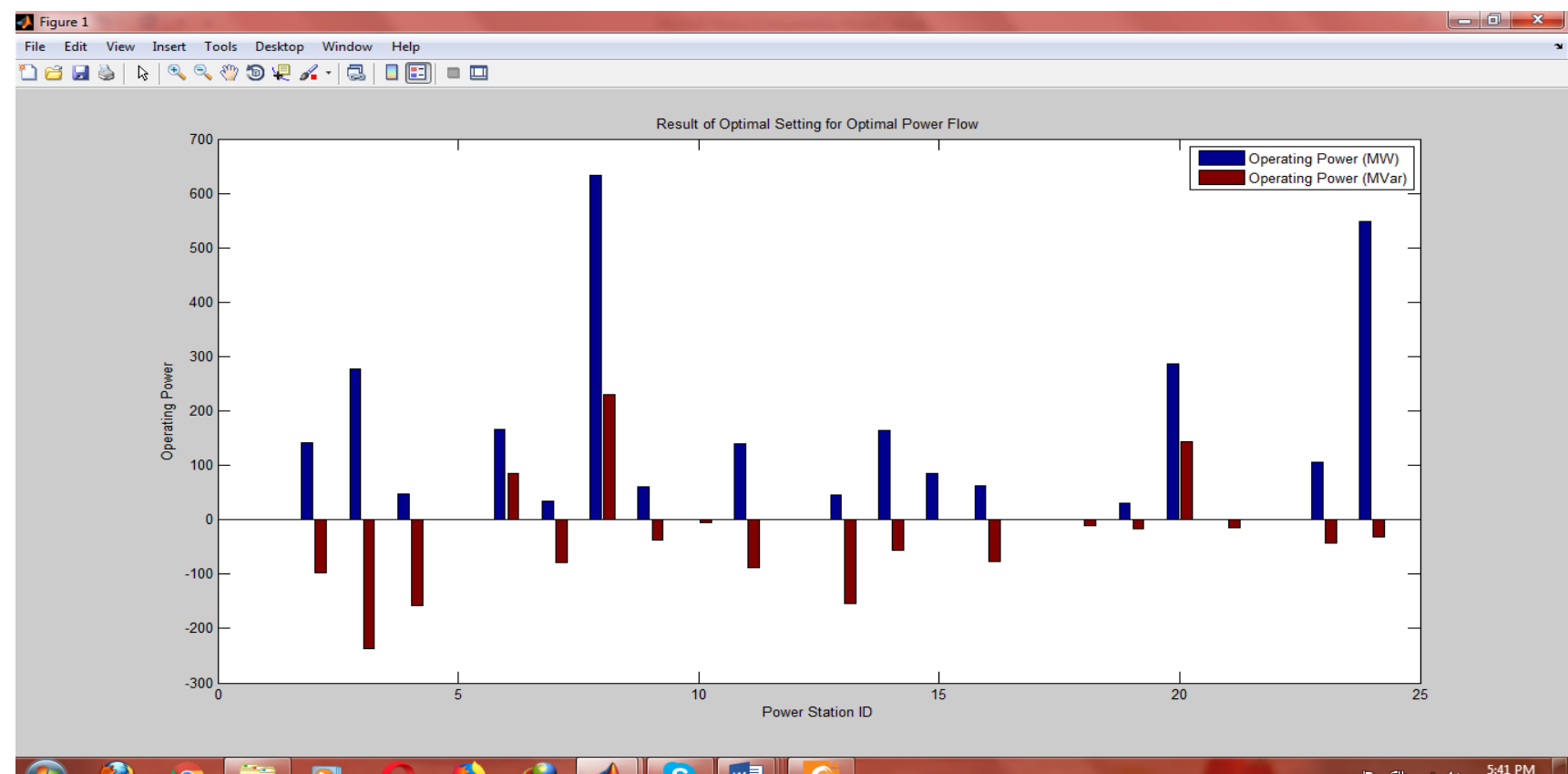

(29) (3) 9 固 
From the above analysis, not all the power generating stations in the entire network will be generating power at the same time, this will minimise the total cost of generation in the network as energy will be saved from the installed capacity. This is indicated in Table 2 and illustrated in Figure 4. The real and reactive power losses in the entire network is reduced to 45.41MW and 257.98MVar respectively.

Table 2: Saved Power from Installed Capacity of Proposed Integrated Generating Stations

\begin{tabular}{|c|l|c|c|c|}
\hline S/N & $\begin{array}{c}\text { Name Of Generating } \\
\text { Station }\end{array}$ & $\begin{array}{c}\text { Installed Capacity } \\
\text { Of Power } \\
\text { Generation } \\
\text { (MW) }\end{array}$ & $\begin{array}{c}\text { Optimal Power } \\
\text { Flow From } \\
\text { Simulation } \\
\text { (MW) }\end{array}$ & $\begin{array}{c}\text { Saved Power } \\
\text { From Installed } \\
\text { Capacity } \\
\text { (MW) }\end{array}$ \\
\hline 1 & Delta 1 & 900 & 0 & 900 \\
\hline 2 & Egbin & 1320 & 633.675 & 686.325 \\
\hline 3 & AES & 224 & 0 & 224 \\
\hline 4 & Okpai & 480 & 61.979 & 418.021 \\
\hline 5 & Sapele & 1020 & 105.922 & 914.078 \\
\hline 6 & Afam 1 & 728 & 141.479 & 586.521 \\
\hline 7 & Jebba & 540 & 165.087 & 374.913 \\
\hline 8 & Kainji & 760 & 85.736 & 674.264 \\
\hline 9 & Shiroro & 600 & 548.321 & 51.679 \\
\hline 10 & Afam 3 & 726 & 0 & 726 \\
\hline 11 & Delta 3 & 840 & 166.115 & 673.885 \\
\hline 12 & Papalanto & 335 & 286.806 & 48.194 \\
\hline 13 & Eyean & 451 & 61.19 & 389.81 \\
\hline 14 & Geregu & 414 & 139.578 & 274.422 \\
\hline 15 & Calabar & 561 & 48.023 & 512.977 \\
\hline 16 & Omotoso & 335 & 31.488 & 303.512 \\
\hline 17 & Sapele Nipp & 451 & 0 & 451 \\
\hline 18 & Egbema & 338 & 34.65 & 303.35 \\
\hline 19 & Alaoji & 504 & 276.611 & 227.389 \\
\hline 20 & Ikot abasi 1 & 190 & 0 & 190 \\
\hline 21 & Ikot abasi 3 & 188 & 46.102 & 141.898 \\
\hline 22 & Omoku 3 & 230 & 0 & 230 \\
\hline 23 & Gbaran & 225 & 0.166 & 224.834 \\
\hline 24 & Omoku 1 & 150 & 0 & 150 \\
\hline & Total & 12,510 & $2,832.928$ & $9,677.072$ \\
\hline
\end{tabular}

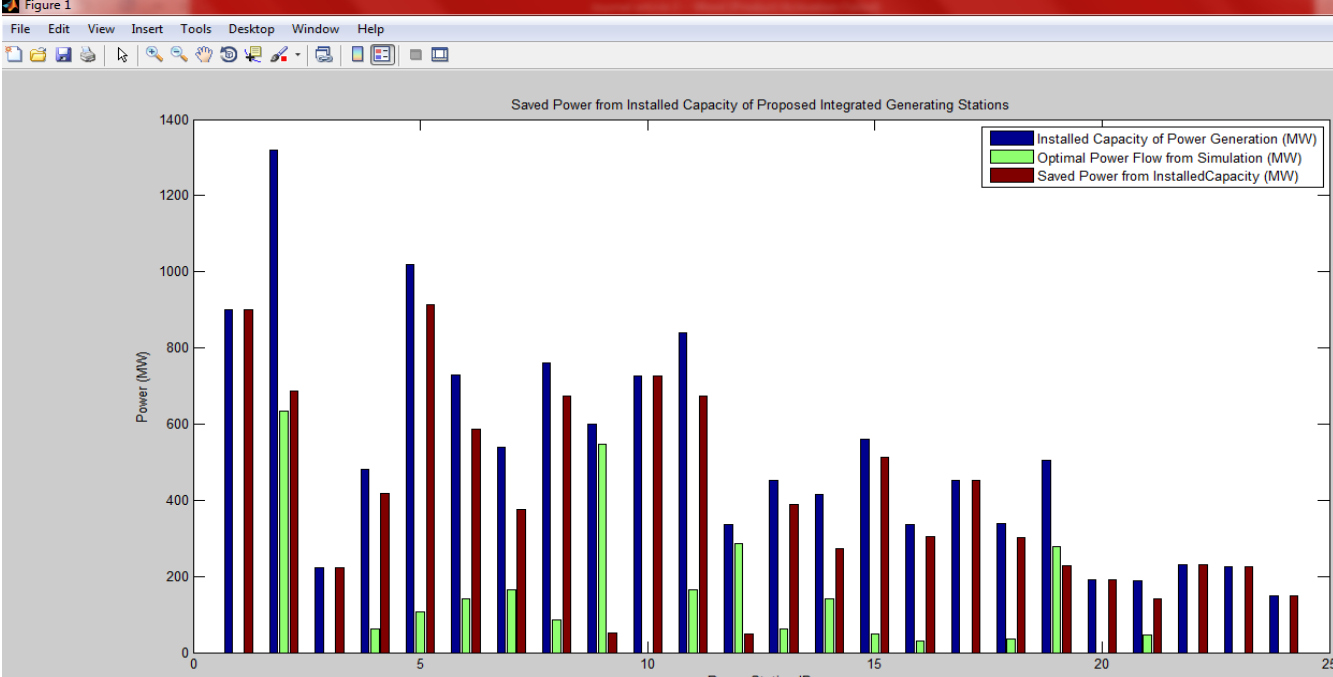


Figure 4: Graph of Saved Power from Installed Capacity of Proposed Integrated Generating Stations

\section{CONCLUSION}

In conclusion, it is more economical for the Proposed Integrated 330KV network to run in optimal power flow mode during off peak period as the load demand during this period is minimal, since power generated cannot be stored. This will eliminate waste in the power generated, save cost and reduced transmission losses in the entire network.

\section{REFERENCE}

Evbogbai M. J. E. (2007). “Electrical Power System Analysis, Planning and Protection”, Denhenry Publishing.

Heydt G. T. (1986). “Computer Analysis Methods for Power System”, Macmilliam Publications New York.

Indulkar C. S., Kothas D. P., and Ramalingam K. (2012). "Power System Transfer”, A Statistical Approach Second Edition, Pages $111-125$

Ogbikaya S., Ike S. and Evbogbai M. J. E. (2019). “Analysis of the Proposed Nigerian 330kV Integrated Network using ETAP 12.6 software”, Scientific Research Journal, Vol. VII, Issue I, Pages 59-71.

Ogbikaya S., Ike S. and Evbogbai M. J. E. (2019). “The Impact of the Proposed Nigeria 330kV Integrated Network on the Transfer Capacity of the Existing 330kV Network", Scientific Research Journal, Vol. VII, Issue I, Pages 72-82.

Onohaebi O.S. (2007). "Reduction of the high technical power losses associated with the Nigerian 330kV Transmission Network", International Journal of Electrical and Electronics Engineering, Vol 1(4), Pages 421-431.

Raju N. V. S. (2014). “Optimization Methods for Engineers”, Pages 215-250.

Weedy B.M. and Cory B. J. (1999). “Electric Power System”, Forth Edition, John Wisey and Sons New York.

William D. and Stevenson Jr. (1988). “Element of Power System Analysis”, Forth Edition Mcgrow Hil Publisher USA. 